\title{
Causes and Effects of the Division Algorithm Applied in Ecuadorian Education
}

\section{Mendoza Velazco Derling José}

Dr. in Education, Department of Experimental Sciences, Universidad Nacional de Educación UNAE, Ecuador, derling.mendoza@unae.edu.ec

Cejas Martínez Magda Francisca

PhD., Universidad Nacional de Chimborazo UNACH and Universidad de las Fuerzas Armadas ESPE, Ecuador, magdacejas09@gmail.com

\section{Navarro Cejas Mercedes}

PhD., Universidad Regional Autónoma de los Andes UNIANDES, Ecuador, ur.mercedesnavarro@uniandes.edu.ec

\section{Flores Hinostroza Elizeth Mayrene}

Dr. in Education, Department of Experimental Sciences, Universidad Nacional de Educación UNAE, Ecuador, elizethfloress2005@gmail.com

Vega Falcón Vladimir

$\mathrm{PhD}$., Universidad Regional Autónoma de los Andes, UNIANDES, Ecuador, ua.vladimirvega@uniandes.edu.ec

The objective of this research was to analyze the causes and consequences of the systematic process of teaching and learning of the division of whole numbers, a study aimed at students and teachers of the 3rd and 4th level of basic education. For its development the qualitative paradigm was used through the modality of field research. As informants, twenty (20) students and two (2) teachers participated. All participants are enrolled in the 3rd and 4th level of the Giordano Bruno School located in the city of Quito, Ecuador. To collect the information, the observation technique and the semi-structured interview were used, and the instruments were subjected to a validity process, where the triangulation was applied. The results were analyzed to give an answer to the proposed objective of the manuscript, where the teaching-learning method applied to the students is presented as a critical-constructivist model, but in reality, a mechanic-academicist education system is used. It was evidenced that teachers shorten the logical processes of the division of whole numbers, by the time-space factor.

Keywords: primary education, teaching, learning, thinking, educational tools

Citation: Mendoza, D., Cejas, M., Navarro, M., Flores, E. \& Vega, V. (2020). Causes and Effects of the Division Algorithm Applied in Ecuadorian Education. International Journal of Instruction, 13(3), 61-74. https://doi.org/10.29333/iji.2020.1335a 


\section{INTRODUCTION}

The advances in education have projected the generalization of different methodologies in the different areas of the education sector. In this sense, the Ministry of Education (2011) has created models and educational guides to support teachers in pedagogical intervention and as a means to enrich teaching and learning processes. These models encourage an approach to the use of didactic, theoretical and systematic resources to expand the possibilities of educational understanding. In the same way, the theoretical and methodological processes for the use of logical thinking in the different educational levels and modalities have been structured. For this, it is conceived that mathematical science is related to other subjects in basic education.

For Stoehr (2017), it is very clear that many students feel apathy for the mathematics subject from the initial education. Apathy or fear of mathematics is often taught by the same teacher who applies it. That is, the teacher is understood by students as analogous to the subject. This problem becomes worse if the teacher uses teaching methods that are not very effective for the student to obtain significant learning, or if the teacher always leaves very complicated tasks without having taught the essentials to the student according to McNaught, (2018).

Many teachers choose to leave these kinds of difficult tasks in order to cause fear. The teacher seeks that his subject is respected by students, but does not realize that he is sowing hatred and fear towards mathematics, whose purpose is to strengthen the brain through problems that are solved with logical processes (Mendoza \& Mendoza, 2018).

In Ecuador, students learn the process of division with whole numbers during the 3rd and 4th grade of primary school. During this learning cycle different operational models are distinguished in the development of mathematical operations (Bulunuz, 2019). In reference to the present investigation, the subtraction and multiplication sums are described by the students as a simple stage, unlike the divisions that is described as a strong and difficult to understand level (Lynch, et al., 2017).

This study focuses on the Giordano Bruno School. As a main problem, the teachers of the school expressed that the students of 3rd and 4th level have a low performance in the applied mathematical evaluations during the cycle B-2018. Therefore, the researchers considered it necessary to analyze the causes and effects of problems in the teaching process of division of the whole numbers, applied by the teachers of the aforementioned staff.

\section{LITERATURE REVIEW}

\section{Constructivist Model}

The constructivist paradigm as the first theoretical model is required by the Ministry of Education (2011) in the Republic of Ecuador. This paradigm is characterized by Duran (2014) as an active process and the construction of the subject, complex, integral and is based on previous conceptual structures. That is to say, learning is a construction by means of which the structure of the mind is modified, thus reaching a greater diversity, 
complexity and integration, each new restructuring implies a return up the spiral of knowledge.

The constructivist approach imposes new challenges. As indicated by Nuket and Cigdem, (2015), this paradigm had its beginnings with Vygotsky (1979), who determines that constructivism plays an important role in the construction of knowledge from experience. Teaching under this approach is conceived as a process through which the student is helped, supported and directed in the construction of knowledge. To help the student in this process, the teacher must start from the conceptual structure of each student, the ideas and preconceptions that already have, because it is from there that the student will provide the first meanings to the subject that is intended to teach.

Within a constructivist perspective, Soler $(2006$, p. 13) considers that the contents should include not only conceptual aspects referring to facts and concepts, but also, and explicitly, the contents referring to procedures, abilities and skills (as is the case of the mathematical procedures). In this order of ideas, the constructivist pedagogical conception recognizes that human learning is a construction of each individual that manages to modify its mental structure. That is, it is considered that knowledge is not received passively but is processed and built by the subject who knows and this learning allows you to organize your experiential and experiential world.

\section{Critical thinking in education}

The second model required by the Ministry of Education (2011) presents the critical thinking by Habermas (1966), who is considered as one of the most outstanding contemporary theorists. In his work 'Theory and Practice', the writer highlights the criticism of the legitimations of the positivist understanding of knowledge, as well as a theory of knowledge that struck his thinking against the scientism. The purpose of the theory is to train individuals through the reflection and understanding of their own thoughts so that they know themselves and facilitate the awareness of the process of educational training that conditions their reality and perception that they have of the same

From this perspective, the research draws to light the assumptions and implicit assumptions of the socio-educational status of the subjects of study, as well as the propositions that do not vary. It is an interesting paradigm for the development of research, as it is important to understand the social roots of critical thinking that is maximized in the school object of study, with respect to the teaching process carried out for the classes of divisions of the whole numbers, in the 3rd and 4th levels of primary education.

\section{Meaningful Learning}

According to Kostiainen, et al., (2018), by contrasting the constructivist system and critical thinking, meaningful learning emerges in education. Meaningful learning, a theory by Ausubel (1968), is then understood as the dimension of knowledge whose cognitive structure must be taken into account, when diagnosing, planning, executing and evaluating the educational action, with attention to previous knowledge, given 
which are the support for the student to acquire and process new ones through the ability to relate them to the concepts that he already has.

It is evident therefore that the origin of the theory of meaningful learning is in the interest that Ausubel has to know, to explain the conditions and properties of learning, which can be related to effective and effective ways to deliberately provoke stable cognitive changes, susceptible to endow with individual and social meaning. Given that what he wants to achieve is that the learning that takes place in the school is significant, the theory of learning must be realistic and scientifically viable to deal with the complex and significant character of verbal and symbolic learning. Likewise, and in order to achieve this significance, you must pay attention to each and every one of the elements and factors that affect you, which can be manipulated for that purpose.

What defines the Ausubelian theory is "meaningful learning", a label that is very present in the dialogue of teachers, curriculum designers and researchers in education and that, however, there are many who also do not know its origin and its justification. Meaningful learning is the process by which a new knowledge or information is related to the cognitive structure of the learner in a non-arbitrary and substantive or non-literal way.

\section{Learning of the Division}

In the Ecuadorian educational system, students begin to prioritize the contents of multiplication in the second level of primary education, with bases in addition and subtraction. Next, the students of 3rd level of primary education initiate the learning process of the division (Ley Orgánica de Educación Intercultural, 2011). After the student knows the strategic systems and tools of multiplication, the student enters a stage of systematic or prolonged learning in time, in which the student internalizes each of the concepts learned and creates a stable knowledge base with those basic concepts about mathematics on which all the other contents that the student must learn will settle.

\section{Knowledge Prior to the Division}

The main previous knowledge with which the students approach the learning of the division and that form the base of this learning are:

- Natural and whole numbers with a maximum of three (3) digits.

- Sorting of the numbers according to their value.

- Concept and development of sum without leads.

- Concept and development of subtraction without leads.

- Concept of Multiplication.

- Multiplication tables from one to nine.

As can be seen, the Ecuadorian educational system when establishing the first contact with the learning of the division requires the basic foundation of addition, subtraction and multiplication. 


\section{Presentation of the Division}

As in the case of multiplication, in Ecuador the concept of division begins to be studied from the second level of basic education. Once the concept of multiplication is known, and therefore, knowing the concept of group or sets, we begin to study the concept of division.

To begin to know this concept, students are usually exposed to activities and problems in which, in a manipulative way, they have to distribute a series of objects among the different exposed groups, being these of distribution or exact distribution and using the object count. to carry out. In this way, the student gets to see the purpose of the division and the concept of sharing a certain amount in equitable sets, interiorizing this concept for the subsequent learning of the operation.

Once the student has understood this concept, without leaving the conceptual and practical stages, he performs more complicated problems that do not reach the abstract stage (notation with symbols and signs).

\section{Notation of the division algorithm}

The division is composed of: the dividend that is what is going to be distributed, the divisor that is the number of parts to be distributed, the quotient that is the result of the operation and the residual that is what remains or remains after doing the cast. The residual is zero when the divisions are exact and different from zero when the division is not exact (Castro \& Morales, 2015).

For Gómez, et al., (2016), the division is composed of four terms which are presented in the following image:

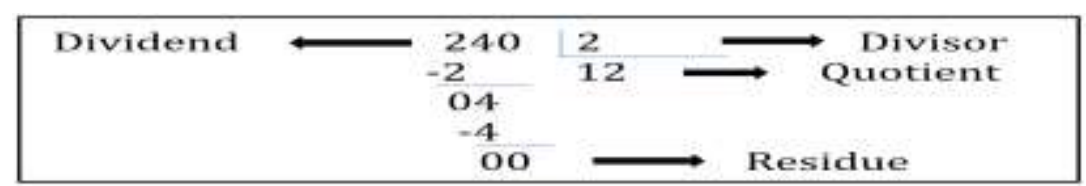

Figure 1

Modern Division Algorithm

The model recommended by the aforementioned authors is similar to that applied in the educational system of Singapore: the operation extends more in space, being recognizable and easy to locate at all times the elements with which the digits operate (divisor, quotient, part of the dividend and the subtractions applied), to be placed on the right, above and below the operation, and not occurring a collision of these numbers in the case of being too large operation.

From a conceptual point of view, division, on the other hand, is not always exact, and the quotient is not only the result of the application of the operator to the operator. The true result is the pair (quotient and residue), where the residual can be zero. In this way, according to image 1, dividing 240 (dividend) by 2 (divisor), the result is 12 (quotient) plus 00 (residual). This makes explicit the need to take the waste into account as a fundamental part of the operation of the division; this statement shows that division is not the inverse operation of multiplication. 
To perform the operation of the division must use other operations than multiplication, the same happens when you want to check it. In the plane of the operative rules, the division is evidently the most complex of the four operations, because it implies at the same time the subtraction, the multiplication and the search by trial or squaring of the quotient figures according to Vergnaud, (1991).

\section{METHOD}

By virtue of the methodology, it was considered pertinent to carry out the research within the qualitative paradigm characterized by Hernández, et al., (2014), which seeks to understand the perspective of the participants (subjects or small groups of people to be investigated) about the phenomena that surround them, to deepen their experiences, perspectives, opinions and meanings, that is, the way in which participants subjectively perceive their reality.

\section{Design of the Investigation}

For the purposes of the study, field research was used, according to the Universidad Pedagógica Experimental Libertador (2016), described as a systematic analysis of problems in reality, with the purpose of describing them, interpreting them, understanding their nature and constituent factors, explain their causes and effects, making use of characteristic methods of the paradigms. In relation to the research, the qualitative paradigm was used. The field study is developed by obtaining the data of interest directly from reality; In this sense, the researchers will support information from the informants.

\section{Key Informants}

The selection of informants as indicated by Rojas (2007) was of a homogeneous sampling type, which has the purpose of describing a specific group in depth. The Giordano Bruno school has a total of 450 students, of which, applying the homogeneous type sampling, 10 students of the 3 rd level ( 5 of the masculine gender and 5 of the feminine gender) were selected. From the 4th level, 10 students were selected (5 males and 5 female). For a total of 20 students, the two teachers who work with 3rd and 4th level were also selected.

In short, for the choice of the informants, a workshop with simple and understandable questions was prepared, demonstrating the request for participation. For the selection, the focus group technique, defined by Nyumba, et al., (2017) was applied as a methodology of workshops or meetings with a selected group of individuals with the objective of obtaining information about their points of view and experiences about facts, expectations and knowledge of a subject.

\section{Instruments for Data Collection}

To collect the necessary information in the study, the participant-type observation technique was used, in which the researcher is included in the group, fact or phenomenon observed to obtain the information "from within" (Sanjuan, 2011). This 
technique is in accordance with the research model since the researchers are teaching teachers and specialists in the area of mathematics.

As a second instrument in the collection of data, the semi-structured interview was developed, a technique that provided the necessary information to respond to the emerging concerns of the present investigation, the authors applied the semi-structured interview to the 12 students and then to both teachers, where Hernández, et al., (2014) states that qualitative interviews should be open, without pre-established categories, in such a way that participants express their experiences in the best way and without being influenced by the researcher's perspective or by the results from other studies. For the study in course, some initial questions were raised that were varying and adapting according to the dynamics of the moment.

\section{The questions were the following:}

- What are the fundamental steps to develop for a division of whole numbers?

- Are there other methods to perform a division of integers?

Later, to analyze and contrast the data obtained, both by the informants and the theoretical foundations investigated, the data comparison or triangulation was applied.

\section{FINDINGS}

The researchers requested procedural participation in the development of a division of two integers, randomly selecting a two-digit number (28) as a dividend, then dividing the number 5 . The mathematical operation was to divide the number 28 by 5 . When the operation was carried out, all 12 students proceeded with the same development method presented below:

The researchers requested procedural participation in the development of a division of two integers, randomly selecting a two-digit number (28) as a dividend, then dividing the number 5 . The mathematical operation was to divide the number 28 by 5 . When the operation was carried out, all 12 students proceeded with the same development method presented below:

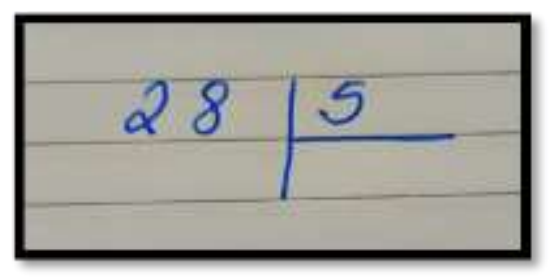

Figure 2

Presentation of a Division of whole Numbers 
In the figure 2 a model of the students is presented to develop the division, the location of the number 28 of the left side (Dividend) is prefixed of some dividing lines of the number 5 (Divisor).

In figure 3 the students expressed: "Here we must grab the first number, that is to say the two (2) and if this number is smaller than we must grab the first two numbers, that is to say the 28 ( 2 and 8 ). Then we have to look for a number that when multiplying by five (5) gives me 28 or approximately, in this case we choose 5 "the chosen number, it is located as a quotient.

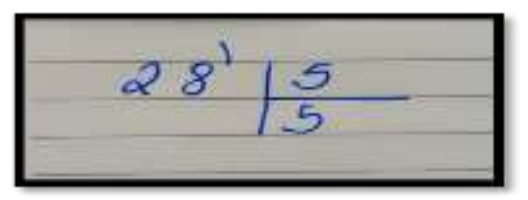

Figure 3

Location of Number 5 in Representation of the Quotient

Students, by placing number 5 as a quotient, express, "then multiply five (5) by five (5) is twenty-five (25) to twenty-eight 28, put three (3)" (See image 4).

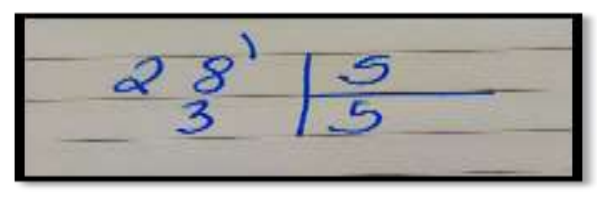

Figure 4

Third step of Division Operation

In figure 5 it is shown that the students place a superior or superscript that shows the limit of the division, expressing "Now, since I do not have any more numbers, I put the zero (0) next to the three (3), now I have thirty (30). As here I put a zero (0), then we must put a comma (,) next to the five (Quotient), then I look for a number that multiplied by five (5) me of thirty (30), and I choose the six (6)".

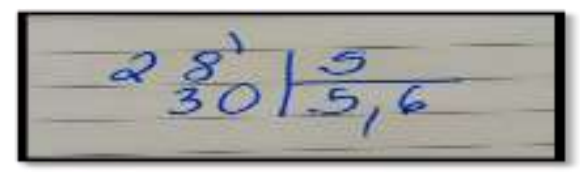

Figure 5

Added six (6) as a Quotient Decimal 
Finally, by establishing the number six (6) as the first decimal of the quotient, the students agree to manifest "now we multiply six (6) by five (5) is thirty (30), thirty (30) is zero $(0)$, and ready gives us five point six $(5,6) "$. Obtaining as residue zero $(0)$.

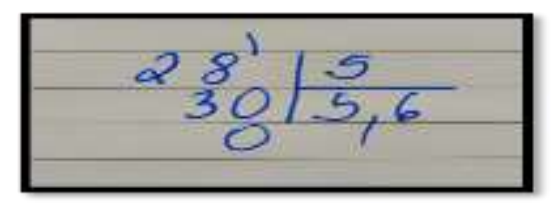

Figure 6

Final Result of the Operation Carried out by the Students

After having requested different operations with different numbers, the students applied the same procedural model of division. The researchers asked the students what the number thirty (30) represents in the division. Students who were asked could not answer the logical representation of the number located, only expressed that what matters is to solve and obtain the final number, the number of the quotient $(5,6)$ (Figure 6).

Together, the authors of the study participated in explaining the same division, providing a consecutive explanation about the operation with a reasoning method (see figure 7).

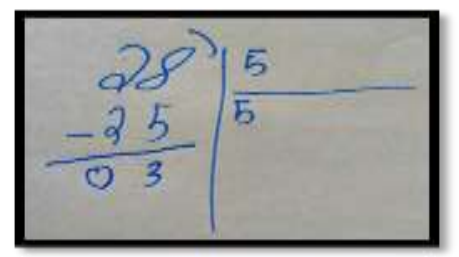

Figure 7

Logical Model - Mathematical

After structuring dividend twenty-eight (28), divisor five (5) and quotient (5), it was explained to students that the result of multiplication five (5) by five (5) can be located at the bottom of the number twenty-eight (28), because there must logically be a subtraction or subtraction. The result of subtracting the twenty-eight (28) minus twentyfive (25) results in three (3).

Then, when determining that the number three as residue is smaller than the divisor (5) (see image 8), a zero (0) to the right of the residue must be supported, making it the number thirty (30) as a residue, also adding a comma (,) to the quotient. 


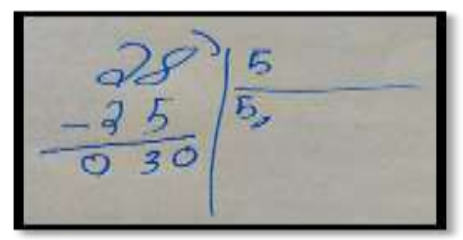

Figure 8

First Subtraction of the Mathematical Operation

In harmony with the steps subscribed by the students, it is aimed at assigning the number six (6) as a decimal attached to the quotient (see figure 9). Because a multiple is required that its result is similar to the residual or smaller value, so the result of the subtraction is zero $(0)$.

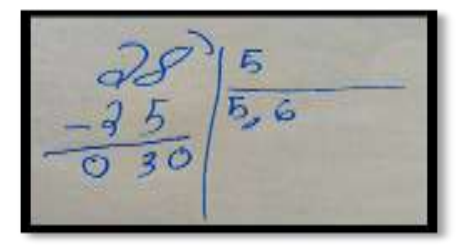

Figure 9

Aggregated Digits for Mathematical Operative Sustenance

The multiplication of the decimal six (6) by the divisor five (5) is applied, obtaining as result thirty, in the same way as in the previous steps the number thirty (30), as a result of the multiplication must be noted in the operation, of this form demonstrates that a subtraction is applied, generating the result zero $(0)$ as final residue (See figure 10).

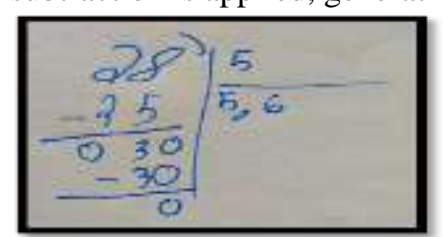

Figure 10

Final Distribution of the Division of whole Numbers

At the conclusion of the divisive model executed by the researchers, the students stated "that type of operation I did not know", "now I understand why I had to say thirty (30), zero (0)". The opinions disseminated by young students, both in their dialect and in writing, show that a mechanical operation is developed where only the final number of the result is of interest, without the need to establish a logical sequence of the origin of each component of the division.

In a joint way they interviewed the participating teachers of the school, who said "in the division of whole numbers we have never applied the subtraction", explaining the lack of strategic knowledge in the development of basic operations in mathematics. They also expressed "when we were in college our teacher gave us the lessons with chalk (plaster) 
and green paint slate." The materials applied by the guidance teachers at the university level in the teaching and learning activities established negative consequences for the current teaching staff. Among other opinions the teachers also indicated "I remember that my teacher was always upset because of the lack of space on the blackboard", they also expressed that "our teacher always looked at the clock to tell us who did the exercise wrong should clear the board and then leave to the recess. "

By triangulating the manifestos on the part of the students, the teachers, the theories that sustain the study and the researchers, it can be determined that the learning process in the school object of study is restricted to an academic classroom. At the Giordano Bruno School, the activities are developed with acrylic blackboard and removable or erasable ink markers, but today teachers reflect the experiences of teachers, who suffered in the past, the need for practical and comfortable materials or utensils, for a better explanation of mathematical operations directed to an approximate number of 25 students.

Based on the type of algorithmic notation for the division, it was determined that the one applied by the Giordano Bruno teachers to their students is the Spanish model (see figure 11).

\begin{tabular}{|lrrr|}
\hline Dividend & 58 & 4 & \\
18 & 14,5 & Divisor \\
20 & & $\longrightarrow$ Quotient \\
& 0 & &
\end{tabular}

Figure 11

Notation of the Division Algorithm used in Spain

In the education system of Spain, the division occupies less space, but there is a great disadvantage, in many cases the student just accumulates numbers between the dividend and the quotient, not calculating well the space they have to leave to perform the operation, which often causes calculation errors.

The style of learning rooted in the Ecuadorian educational system, in a Spanish model, is a type of learning based on the memorization of some theoretical-practical content of each of the steps of the division and put into practice through repetitive exercises, both individual level as a group and through level tests, which mark the scope of the objectives of the students evaluated.

\section{DISCUSSION AND CONCLUSION}

The means of teaching applied in the study, such as the blackboard, pencil, sheets among others, are resources and materials that are used consecutively by teachers for the explanation addressed to a number of students of approximately twenty-five (25), who are at a distance no greater than 10 meters. In this way the teacher favors communication with their students.

The means of support for communication between the teacher and the students were not essentially oral; Visual communication was also privileged. Within this typology, in research, the use of practical materials establishes a better communication and 
understanding for the mathematics lessons. The information that is desired to focus on the part of the teachers is always limited to different factors, as shown by the results of the study, where the teaching and learning activities that the current teachers received were limited by the materials. The Spanish notation model establishes the space factor as an element that shapes the school climate.

The training that the teachers received was not of great symbolic support in the slates, due to the discomfort that the use of the plaster chalk represents. This educational material formerly applied by the training teachers, was to reduce the use of discomfort caused by dust, sound and body fatigue. Because it was an uncomfortable material, teachers reduced their words culturally, reducing short sentences to words, symbols or signs. Similarly, the creation of ideas through ideogenetic drawings.

The contents and mathematical processes suffered a shortening, due to the discomfort that the use of educational materials such as blackboard and chalk gave. Teachers, by decreasing the least amount of writing, reduced the sequentiality to the contents that make up a class. The lack of structuring and order in the information led to the time factor. Teachers did not like to spend so much time in writing, however, the most advisable was to divide the surface, at least, in two areas and write using the technique of columns.

The divisions that failed to generate enough physical space resulted in the imaginary or mental tracing of steps that were not written on the board. That is, by avoiding words, numbers steps or normal methods, areas were reserved to write about them in an imaginary way. The lack of logical sequence in the activities written on the blackboard, caused a vacuum in the explicit operation of the logical subtraction, which determines the harmonic succession that prevails in the mathematical divisions.

Therefore, based on the conclusions described, it is recommended to determine a better sequence and logical order in the explanation of the mathematical lessons; differentiate its different parts and components of each of them. Also emphasize and offer visual variety in the writing in a way that increases motivation and encourages retention in elementary school students. In order to draw attention to the operation of integer divisions, it is convenient to call attention with graphic resources such as underlines, lines, arrows or colors, which indicate the operation that is applied, that is, symbolize it in a visible way and not expose it as a verbal or imaginary treaty, since it slows down the development of logical-mathematical thinking in elementary school students. Throughout the writing it is advisable not to use abbreviations or establish procedural leaps, unless they are of widespread use among students.

In the blackboard the teachers should not write the obvious. It is not worth the effort to reduce the number of words or numbers just to increase the time. It must be remembered that, for the student, everything that appears on the board has a reason. All the mathematical operations that the student reads are substantial. His presence is a testimony of the exposed and as such should be considered.

Finally, answers can be given to the questions raised. Concluding that there are different methods to carry out a whole number operation. There are two division algorithms. The 
first is called Spanish division algorithm. This model is currently implemented by the Ecuadorian Ministry of Education. Also applied by teachers in the institution under study. A process of few steps, but difficult to understand. The second is called modern division algorithm. This model is recommended to be applied demonstrating that students understand more easily. A process of more steps, but easy to understand. The second is called modern division algorithm. This model is recommended to be applied demonstrating that students understand more easily.

\section{REFERENCES}

Ausubel, D. (1968). Educational psychology: A cognitive view. New York: Holt, Rinehart, and Winston.

Berkoski, K (2016). Understanding the connections between the brain, mind, and society. Journal of Constructivist Psychology, 30(3), 315-319. DOI: https://doi.org/10.1080/10720537.2016.1238790.

Bulunuz, N. (2019). Introduction and assessment of a formative assessment strategy applied in middle school science classes: Annotated student drawings. International Journal of Education in Mathematics, Science and Technology (IJEMST), 7 (2), 186196. DOI:10.18404/ijemst.552460.

Castro, M., \& Morales, M. (2015). Classroom environments that promote learning from the perspective of school children. Educare Electronic Journal, 19(3), 1-32. DOI: http://dx.doi.org/10.15359/ree.19-3.11.

Durán, P. (2014). Reflections on the pedagogical value of constructivism. Ideas $y$ Valores, 63(155), 171-190. https://dx.doi.org/10.15446/ideasyvalores.v63n155.37181.

Gómez, B., Figueras, O., \& Contreras, M. (2016). Teaching models for algorithms of fraction's division. Avances de Investigación en Educación Matemática, 9, 43 - 63.

Habermas, J. (1966). Teoría y práctica: Ensayos de filosofía social. Sur, Buenos Aires.

Hernández, R. Fernández, C., \& Baptista, P. (2014). Metodología de la investigación. México: McGrawHill.

Kostiainen, E., Ukskoski, T., Ruohotie, M., Kauppinen, M., Kainulainen, J., \& Mäkinen, T. (2018). Meaningful learning in teacher education. Teaching and Teacher Education, 71, 66-77. DOI: 10.1016/j.tate.2017.12.009.

Ley Organica de Educacion Intercultural Codificado (2011). Ministerio de Educación. Ecuador. Retrieved from https://educacion.gob.ec/wpcontent/uploads/downloads/2017/05/Ley-Organica-Educacion-Intercultural-

Codificado.pdf.

Lynch, S., Spillane, N., House, A., Burton, E., Behrend, T., Ross, K., \& Han, E. (2017). A policy-relevant instrumental case study of an inclusive STEM-focused high school: Manor new tech high. International Journal of Education in Mathematics, Science and Technology, 5(1), 1-20. DOI:10.18404/ijemst.75656. 
McNaught, C. (2018). Enhancing research papers into effective teaching and meaningful learning in mathematics, science and technology education in Africa. Eurasia Journal of Mathematics, Science and Technology Education, 14 (8), em1576. DOI: https://doi.org/10.29333/ejmste/92115.

Ministerio de Educación, (2011). Libro del docente, didáctica de las matemáticas. Quito: Coordinación general de administración escolar - MinEduc. [Online] Retrieved from https://educacion.gob.ec/wp-content/uploads/downloads/2013/03/SiProfeDidactica-Matematicas.pdf.

Mendoza, D. J., \& Mendoza, D. I. (2018). Information and communication technologies as a didactic tool for the construction of meaningful learning in the area of mathematics. International Electronic Journal of Mathematics Education, 13(3), 261-271. DOI: https://doi.org/10.12973/iejme/3907.

Nyumba, T., Wilson, K., Derrick, C., \& Mukherjee, N. (2017). The use of focus group discussion methodology: Insights from two decades of application in conservation. Methods in ecology and evolution, 9(1), 20-32. Special Feature: Qualitative methods for eliciting judgements for decision making. DOI: 10.1111/2041-210X.12860.

Nuket, G., \& Cigdem, H. (2015). Constructivism in teaching and learning; Content analysis evaluation. Procedia - Social and Behavioral Sciences, 191 (2), 526-533.

Rojas, B. (2007). Investigación cualitativa. Caracas: FEDUPEL.

Sanjuan, L. (2011). La Observacion. Mexico: UNAM.

Soler, E. (2006). Constructivismo, innovación y enseñanza efectiva. Caracas: Equinoccio.

Stoehr, K. (2017). Mathematics anxiety: One size does not fit all. Journal of Teacher Education, 68 (1), 69-84.

Universidad Pedagógica Experimental Libertador, (2016). Manual de Trabajos de Grado de Especialización y Maestría y Tesis Doctorales. Caracas: FEDUPEL.

Vergnaud, G. (1991). El niño, las matemáticas y la realidad. Problemas de la enseñanza de las matemáticas en la escuela primaria. México: Trillas.

Vygotsky, L. (1979). El desarrollo de los procesos psicológicos superiores. Barcelona: Crítica. 